\title{
DETERMINATION OF DRY MATTER PERCENTAGE OF EJACULATED AND EPIDIDYMAL BULL SPERMATOZOA AFTER DIFFERENTIAL FLOTATION*
}

\author{
U. LAVON, R. VOLCANI AND D. DANON $\dagger$ \\ Department of Animal Science, Volcani Institute of Agricultural Research, \\ and $\dagger$ Weizmann Institute of Science, Rehovot, Israel \\ (Received 18th November 1967, revised 15th March 1968)
}

Previous estimates of dry matter content in spermatozoa have been variable (Ray Sarkar, Luecke \& Duncan, 1947; VanDemark, 1948; Barer, Ross \& Tkaczyk, 1953) but some of the methods employed might have altered the chemical composition of the spermatozoa. Therefore, a method was needed that would facilitate the separation of spermatozoa from seminal plasma and, at the same time, would ensure minimal exchange of water and other substances to and from the cells.

Ballentine \& Burford (1960) have separated, simply and effectively, various cells from their suspending medium by differential flotation (DF). Our previous studies on the specific gravity (sp.gr.) and density distribution of bull spermatozoa were based on DF. The spermatozoa thus separated from the seminal plasma are not altered in their composition as by washing with water and various salt solutions, and it was therefore thought to be a useful method for direct determination of the dry matter percentage. The correctness of this assumption has been borne out by the experimental results of this study.

Fresh ejaculated semen collected with the aid of an artificial vagina was centrifuged at $3000 \mathrm{~g}$ for $10 \mathrm{~min}$ to remove most of the seminal plasma. The concentration of the cells resuspended in the residual seminal plasma was about $3 \times 10^{9} \mathrm{cells} / \mathrm{ml}$ and this was introduced into $0.4-\mathrm{ml}$ capacity polyethylene Microfuge tubes containing $0.05 \mathrm{ml}$ of phthalate esters mixture of predetermined sp.gr., ranging, as a rule, from 1.040 to 1.050 . The tubes were centrifuged at $10,000 \mathrm{~g}$ for $5 \mathrm{~min}$ in a Beckman 152 Microfuge.

Epididymal spermatozoa were sufficiently concentrated to be placed directly in the polyethylene micro-tubes.

Following centrifugation, foreign matter denser than spermatozoa precipitates at the bottom of the test tube and is removed by cutting off the tip of the tube. A second cut is made below the interphase between the phthalate and the cells, avoiding contamination of the packed cells with the separating fluid. Material lighter than the separating fluid, i.e. seminal plasma and remnants of cells, is discarded. The sedimented cells are transferred into a weighed 5-ml

* Contribution from The Volcani Institute of Agricultural Research (N.U.I.A.), Rehovot, Israel. 1967 Series, No. 1239-E. 
beaker with the aid of a needle and dried at $110^{\circ} \mathrm{C}$ for 18 to $20 \mathrm{hr}$ in an oven or lyophilized. The sample is cooled in a vacuum desiccator over anhydrous sodium sulphate for $4 \mathrm{hr}$. Duplicates of calculated dry matter percentage agree within 0.05 to $0.15 \%$.

The separated spermatozoa were checked for phthalate esters contamination by extraction with di-ethyl ether and analysis by thin-layer chromatography (Stahl, 1965). No trace of phthalate esters was found in four trials.

Semen samples were collected weekly from six bulls for about 2 months (January to March, 1967). The semen was placed in Thermos bottles at $5^{\circ} \mathrm{C}$ until tested. Only ejaculates that showed satisfactory motility at $38^{\circ} \mathrm{G}$ under the microscope were used.

Four consecutive ejaculates were collected (in March 1967) from each of nine bulls after 21 days of abstinence.

Spermatozoa from the caput and the cauda epididymidis were collected according to Grogan, Mayer \& Sikes (1966), from ten testes removed from ten bulls, 14 to 16 months old, immediately after slaughter. The mediastinum testis did not yield sufficient amounts of spermatozoa and the small amounts collected were contaminated with blood.

Separation of spermatozoa from seminal plasma and from foreign matter was successfully achieved. When re-mixed with seminal plasma after DF, the spermatozoa regained much of their initial motility.

The percentage of dry matter in ejaculated bull spermatozoa collected from six bulls ranged from 26.59 to 32.72 , with an average of $29 \cdot 74$. The variation within the individual bulls was 3 to $5 \%$.

The percentage of dry matter in spermatozoa collected from four consecutive ejaculates was $31.09,32.59,32.31$ and 32.04 from the first to the fourth, respectively. The percentage of dry matter increased from the first to the second ejaculate and tended to decrease from the second to the fourth, but the differences were not significant.

The mean dry matter percentage of spermatozoa collected from the caput was $29 \cdot 01 \pm 0.29$, and that of the cauda epididymidis was $31 \cdot 52 \pm 0.29$.

Ballentine \& Burford (1960) have shown the efficiency of the DF in separating cells from their suspending medium. This method has been proved in the present study to be useful and effective in separating spermatozoa from the seminal plasma, foreign matter and cell debris present in the semen.

Giberman (personal communication) has shown that the trapped volume between red cells separated by DF is about 1.6 to $0.2 \%$. Assuming $10 \%$ dry matter in the seminal plasma and about $2 \%$ trapped volume, the error introduced is of the order of $0.2 \%$ and, therefore, negligible. This method avoids washing the spermatozoa, which may alter the cells (Hartree \& Mann, 1959).

Calculating the dry matter percentage based on the specific gravity of the cells, their volume, the dry matter in seminal plasma and in whole semen, is elaborate. Furthermore, it is subject to error because of the difficulty in estimating the volume of the cell fraction which depends on the centrifugal force applied. Different values for the volume of spermatozoa were given by Hickman (1958), Foote (1958) and Shaffner \& Andrews (1943).

The values of percentage dry matter obtained in the present study for 
ejaculated spermatozoa are higher than those reported by Ray Sarkar et al. (1947) and by VanDemark (1948), and lower than those reported by Barer et al. (1953).

If specific gravity values for spermatozoa, as reported by Lavon, Volcani, Amir \& Danon (1966a, b), and the chemical composition of the dry matter given by Mann (1964) are used for computing the dry matter of spermatozoa, the results are in close agreement with those obtained in the present study.

The dry matter content is higher in spermatozoa collected from the cauda than in those collected from the caput epididymidis. This is in agreement with the higher sp.gr. of the cells as the spermatozoa advance along the reproductive tract (Lavon et al., 1966b). When consecutive ejaculates were collected, the differences between them were not significant. It is concluded that the higher sp.gr. of the older spermatozoa may be partly due to dehydration. To find out whether other factors are involved requires a comparative study of the composition of the cells of different age groups.

This study is part of a thesis to be submitted by the senior author in partial fulfilment of the requirements for a Ph.D. degree from the Hebrew University of Jerusalem and has been financed in part by a grant awarded by the United States Department of Agriculture under P.L. 480. The authors are indebted to $\mathrm{Mr} \mathrm{D}$. Zismann for his technical assistance.

\section{REFERENCES}

Ballentine, R. \& Burford, D. D. (1960) Differential density separation of cellular suspension. Analyt. Biochem. 1, 263.

Barer, R., Ross, K. F. A. \& Tkaczyk, S. (1953) Refractometry of living cells. Nature, Lond. 171, 720.

Foote, R. H. (1958) Estimation of bull sperm concentration by packed cell volume. F. Dairy Sci. 41, 1109.

Grogan, D. E., MAYER, D. T. \& Sikes, J. D. (1966) Quantitative differences in phospholipids of ejaculated spermatozoa and spermatozoa from three levels of the epididymis of the boar. $\mathcal{F}$. Reprod. Fert. 12, 431.

Hartree, E. F. \& MANN, T. (1959) Plasmalogen in ram semen and its role in sperm metabolism. Biochem. 7. 71, 423.

Hickman, C. G. (1958) Spermatocrit values in facilitating the estimation of spermatozoa concentration. F. Dairy Sci. 41, 318.

Lavon, U., Volcani, R., Amir, D. \& Danon, D. (1966a) The specific gravity of bull spermatozoa and seminal plasma. F. Reprod. Fert. 11, 447.

Lavon, U., Volcani, R., Amir, D. \& Danon, D. (1966b) The specific gravity of bull spermatozoa from different parts of the reproductive tract. F. Reprod. Fert. 12, 597.

MANN, T. (1964) The biochemistry of semen and of the male reproductive tract. Methuen, London.

Ray Sarkar, B. C., Luecke, R. W. \& Duncan, C. W. (1947) The amino acid composition of bovine semen. F. biol. Chem. 171, 463.

ShaffNer, C. S. \& ANDREws, F. N. (1943) The determination of the concentration of spermatozoa in fowl and bull semen. Anat. Rec. 86, 99.

Stahl, E. (1965) Thin-layer chromatography. Springer-Verlag, Berlin; Academic Press, New York.

VANDEMARK, N. L. (1948) The relation of spermatozoa metabolism and other semen characteristics to the livability of bovine spermatozoa in different nutrient diluters. Ph.D. thesis, Cornell University, Ithaca, New York. 